\title{
Creutzfeldt-Jakob disease and lyophilised dura mater grafts: report of two cases
}

\author{
T Esmonde, C J Lueck, L Symon, L W Duchen, R G Will
}

\begin{abstract}
Two further cases of Creutzfeldt-Jakob disease (CJD) in association with cadaveric dura mater grafts are described. The clinical features of all such reported cases resemble more closely those of sporadic $\mathrm{CJD}$, in contrast with kuru and the cases of CJD which have arisen after therapy with human pituitary-derived growth hormone. This observation may reflect the route of inoculation of the agent.
\end{abstract}

(F Neurol Neurosurg Psychiatry 1993;56:999-1000)

Circumstantial evidence suggests that iatrogenic transmission of CJD has occurred via human pituitary derived hormones, neurosurgery, depth electrodes and corneal graft. ${ }^{1}$ Cadaveric human tissue has also been implicated in seven cases, of which six involved dura mater grafts and one pericardial tissue. ${ }^{2-8}$ We describe two further cases of CJD that developed following the insertion of lyophilised dura mater grafts during neurosurgical procedures.

\section{Case reports}

CASE 1

A 38 year old woman was diagnosed as suffering from cerebellar ectopia and syringohydromyelia in 1965. She had suboccipital craniotomy and C1, 2 laminectomy for decompression in 1969 with insertion of a cadaveric dura mater graft. A recurrence of symptoms necessitated D2, 3, 4, 5 laminectomies for a syringostomy in 1976 .

In 1978 she re-presented with a six week history of increasing lower limb stiffness, loss of balance, and pain in the left upper limb. Examination revealed normal higher mental functions and apart from a suggestion of cerebellar dysarthria, the cranial nerves were normal. Motor and sensory examination indicated a deterioration in the signs relating to syringomyelia and at re-operation a fresh Pudenz ventricular catheter was introduced.

Two days after the operation, nystagmus on left lateral gaze was noted, and the other physical signs were unchanged. Seventeen days postoperatively she required help to walk and four weeks after surgery she became withdrawn and tearful although there was no evidence of cognitive decline. Despite antidepressants she continued to be withdrawn and seemed terrified at the approach of medical and nursing staff. Jerking of the upper limbs developed and an EEG was diffusely abnormal with frequent short discharges of high voltage slow activity. Further EEGs showed the classic repetitive triphasic complexes typical of CJD. Haematological, biochemical and CSF examinations failed to reveal any abnormality to account for her condition. CT brain scan was also normal. She became akinetic and mute and died six months after the initial admission. Postmortem was not performed.

\section{CASE 2}

A 44 year old stock controller was admitted to the National Hospital for Neurology in March 1991, complaining of visual disturbance, dyslexia, dysgraphia and word-finding difficulties.

Eight years previously she had presented with a four year history of headache followed by visual disturbance and was found to have a left-sided meningioma arising from the petrous temporal bone. The tumour was surgically excised and at the operation the defect in the dura was replaced with cadaveric lyophilised dura ("Lyodura"). Postoperatively she was mildly dyslexic, dyscalculic and dysarthric, but these symptoms improved over the next few years and she was able to return to work.

In January 1991 she developed metamorphopsia and micropsia, most marked in the left visual field and this was followed by progressive dyslexia, dysgraphia and word-finding difficulties. She became tearful and emotionally labile and in the week before admission became unsteady on her feet. A CT scan was performed in outpatients two weeks before her admission but was unchanged from a previous scan in 1988 which showed no evidence of tumour recurrence.

On admission she was orientated in time and place, but she had marked nominal dysphasia with neologisms and paraphasias. She could not read or write and showed marked apraxia. There was a suggestion of a right hemianopia, a mild right upper motor neuron facial weakness on the right and a mild right 
hemiparesis. Plantar responses were bilaterally flexor and sensory testing was impossible.

Routine haematological and biochemical indices were normal. CSF showed 18 red cells, one white cell and a protein of $0.39 \mathrm{~g} / 1$ with a normal glucose. An EEG performed on the day of admission showed marked slow wave activity with a clear left-sided predominance. A subsequent EEG under the influence of diazepam gave similar results.

On the day following admission she developed myoclonus of the outstretched arms and over the next few days this spread to involve the whole body. Over the course of the ensuing two months, her clinical state deteriorated rapidly with the development of visual hallucinations and progressive dementia. She developed a chest infection and died in May 1991.

A limited post-mortem examination was carried out. At the site of the previously removed meningioma, there was dense adhesion of shrunken atrophied cerebellar folia to the overlying graft which was partly calcified, but no evidence of tumour recurrence. The left posterior temporal and occipital regions were irregularly shrunken. Blocks taken from many regions of cerebral hemispheres, brain stem and cerebellum were embedded in paraffin wax and examined using a wide range of histological methods. There were spongiform changes and astrocytic hyperplasia characteristic of CJD in all regions of the cerebral cortex affecting the occipital cortex with greatest severity. Spongiform change and gliosis were also marked in basal ganglia and cerebellum, in both molecular and granular layers, as well as in the grey matter of the brainstem. There was severe depletion of the Purkinje and granule cells. A careful search for amyloid deposits was made but none were found.

\section{Discussion}

There have been six cases of CJD in dura mater recipients described in previous reports $^{2-7}$ and the features of all these cases together with our own (cases 1 and 2) are listed in the table. The age of onset of the disease is dependent on the time at which the graft was introduced. The latency to appearance of initial symptoms ranges from 19-120 months with a mean of 59 months. The duration of illness is a mean of 8.3 months with a range of 4-18 months and this is in keeping with cases of sporadic CJD.

Table Clinical features of CfD in dura mater recipients

\begin{tabular}{|c|c|c|c|c|c|c|c|}
\hline Case number & $\begin{array}{l}\text { Age } \\
\text { onset }\end{array}$ & Sex & Latency* & $\begin{array}{l}\text { Illness } \\
\text { duration } \\
\text { (months) }\end{array}$ & $E E G$ & $C T$ & $\begin{array}{l}\text { Initial } \\
\text { symptoms }\end{array}$ \\
\hline $\begin{array}{l}1 \\
2\end{array}$ & $\begin{array}{l}51 \\
44\end{array}$ & $\begin{array}{l}F \\
F\end{array}$ & $\begin{array}{l}84 \\
96\end{array}$ & $\begin{array}{l}6 \\
4\end{array}$ & $\begin{array}{l}\text { Typical } \\
\text { Slow }\end{array}$ & $\begin{array}{l}\text { Normal } \\
\text { Previous } \\
\text { surgery }\end{array}$ & $\begin{array}{l}\text { Mood } \\
\text { Visual }\end{array}$ \\
\hline $\begin{array}{l}\text { 3(Masullo et al) } \\
\text { 4(Thadani et al) } \\
\text { 5(Miyashita et al) } \\
\text { 6(Nisbet et al) } \\
\text { 7(Willison et al) } \\
\text { 8(Pocchiari et al) }\end{array}$ & $\begin{array}{l}27 \\
28 \\
26 \\
25 \\
32 \\
32\end{array}$ & $\begin{array}{l}M \\
F \\
F \\
M \\
F \\
F\end{array}$ & $\begin{array}{l}44 \\
19 \\
33 \\
31 \\
120 \\
120\end{array}$ & $\begin{array}{l}\mathrm{N} / \mathrm{S} \dagger \\
4 \\
18 \\
14 \\
4 \\
8\end{array}$ & $\begin{array}{l}\text { N/S } \\
\text { Slow } \\
\text { Typical } \\
\text { N/S } \\
\text { Slow } \\
\text { Slow }\end{array}$ & $\begin{array}{l}\text { N/S } \\
\text { Normal } \\
\text { Atrophy } \\
\text { N/S } \\
\text { Atrophy } \\
\text { Atrophy }\end{array}$ & $\begin{array}{l}\text { Confusion } \\
\text { Ataxia } \\
\text { Ataxia } \\
\text { Dementia } \\
\text { Dementia } \\
\text { Dementia }\end{array}$ \\
\hline
\end{tabular}

All the reported patients became demented.

${ }^{\star}$ Latency $=$ time in months from insertion of graft to appearance of first symptoms. $\dagger$ NS = not stated.
The initial symptoms included cognitive decline in four, and dementia developed in all cases. This is in contrast to those cases in which the disease was acquired through human pituitary-derived extracts in which the presenting features were predominantly those of cerebellar involvement. This provides further support to the hypothesis that the route of inoculation of the infectious agent is a major determinant to the clinical presentation.

Electroencephalography is often used as a diagnostic aid in cases of suspected CJD. However, the characteristic appearances of generalised synchronous repetitive biphasic or triphasic complexes is not always seen and this appearance may depend on the timing of performance of the EEG. Of the eight cases of CJD described following dura mater grafts only two showed repetitive complexes.

Although the term "slow virus disease" is now out of fashion, the latent period of many years before disease becomes apparent in iatrogenic CJD reinforces the potentially prolonged incubation period in the spongiform encephalopathies. The presumption is that dura mater for grafting was obtained from an individual or individuals who died of CJD and the occurrence of accidental transmission in two cases treated 13 years apart strongly suggests that more than one batch of dura mater was contaminated. There is inevitably a prolonged interval between the use of contaminated materials and the recognition of the risk of CJD, and the protocols to ensure that human-derived tissues for implants and medicinal products are not derived from individuals dying of CJD cannot be foolproof. It is possible that further cases of iatrogenically induced CJD will arise in individuals who have already received dura mater grafts, but new exposures cannot now occur as these products are no longer available in the United Kingdom.

The occurrence of CJD in individuals exposed to pituitary-derived hormone and dura mater grafts suggests the necessity for careful risk/benefit analysis in the use of any therapeutic product derived from human CNS tissues or adjacent structures.

We thank Dr. R Ross-Russell for permission to report case 2 .

1 Brown P, Preece MA, Will RG. 'Friendly fire' in medicine: hormones, homografts, and Creutzfeldt-Jakob discine: hormones, homografts,

2 Masullo C, Pocchiari M, Macchi G, Alema G, Piazza G, Panzera MA. Transmission of Creutzfeldt-Jakob disease by dural cadaveric graft (Letter). F Neurosurg 1989; 1:954-5.

3 Thadani V, Penar PL, Partington J, et al. Creutzfeld-Jakob disease probably acquired from a cadaveric dura mater graft. $\mathcal{F}$ Neurosurg 1988;69:766-9.

4 Miyashita $\mathrm{K}$, Inuzuka $\mathrm{T}$, Kondo $\mathrm{H}$, et al. CreutzfeldtJakob disease in a patient with a cadaver dura graft. Neurology 1991;41:940-1.

5 Nisbet TJ, MacDonaldson I, Bishara SN. CreutzfeldtJakob disease in a second patient who received a cadaveric dura mater graft. $\mathscr{f} A M A 1989 ; 261: 1118$.

6 Willison HJ, Gale AN, McLaughlin JE. Creutzfeldt-Jakob disease following cadaveric dura mater graft. $¥ N N P$ 1991;54(10):940.

7 Pocchiari M, Masullo C, Salvatore M, Genuardi M, Galgani S. Creutzfeldt-Jakob disease after non-commercial dura mater graft. Lancet 1992;340:614-5.

8 Tange RA Troost D Limburg M. Progressive fatal dementia (Creutzfeldt-Jakob disease) in a patient who received homograft tissue for tympanic membrane closure. Eur Arch Otorhinolaryngol 1990;247:199-201. 